\title{
NILAI-NILAI MORAL-EDUCATION DI LINGKUNGAN MASYARAKAT SOSIAL DALAM GURINDAM DUA BELAS KARYA RAJA ALI HAJI
}

\author{
Oleh: Nofmiyati \\ SMAN Plus Riau \\ Email: nofmi.miftah@gmail.com
}

\begin{abstract}
:
Raja Ali Haji menyakini bahwa manusia adalah ciptaan Allah dan pada akhirnya kembali kepada-Nya. Namun bukan berarti manusia melupakan kehidupannya sebagai anggota masyarakat. Islam memberikan kepada manusia tolak ukur yang pantas untuk memenuhi kebutuhan psikologisnya, termasuk di dalamnya hidup dengan masyarakat dengan menghargai cinta diri dan bukan egoisme. Cinta diri adalah suatu tanda kebesaran spiritual dan kepribadian yang besar, yang mendorong manusia ke arah sederhana dan pengorbanan.
\end{abstract}

Kata Kunci: cinta, ego, moral 


\section{NILAI-NILAI MORAL-EDUCATION DI LINGKUNGAN MASYARAKAT SOSIAL DALAM GURINDAM DUA BELAS KARYA RAJA ALI HAJI}

\section{Oleh: Nofmiyati \\ SMAN Plus Riau \\ Email: nofmi.miftah@gmail.com}

\section{Pendahuluan}

Pengertian etimologis Moral yang berasal dari bahasa Latin Mores jamak Dari mos, adalah adat kebiasaan. Dalam bahasa Indonesia moral diterjemahkan dengaan arti susila. Yang dimaksud moral adalah sesuai dengan ide-ide yang umum diterima oleh tindakan manusia, mana yang baik dan wajar. ${ }^{1}$ Disamping itu ada juga perkataan akhlak yang berasal dari bahasa Arab khuluqun yang berarti budi pekerti, perangai, tingkah laku atau tabi'at. Perumusan pengertian akhlak timbul sebagai media yang memungkinkan adanya hubungan baik antara kholiq dengan makhluk dan antara makhluk dengan makhluk. Menurut Ahmad Amin pengertian akhlak adalah suatu ilmu yang menjelaskan arti baik dan buruk, menerangkan apa yang seharusnya dilakukan setengah manusia kepada lainnya, menyatakan tujuan yang harus dituju oleh manusia dalam perbuatan mereka, dan menunjukkan jalan untuk melakukan apa yang harus diperbuat. ${ }^{2}$

Selain istilah akhlak juga lazim dugunakan istilah etika. Kata ini bersal dari bahasa Yunani ethos yang berarti adat kebiasaan. Pengertian etika menurut filsafat adalah ilmu yang menyelidiki

\footnotetext{
${ }^{1}$ Hamzah Ya'qub, Etika Islam pembinaan Akhlakul Qarimah (suatu penghantar) (Bandung: Diponegoro, 1983).

${ }^{2}$ Ibid.hlm.11-12

52 Jurnal Madania: Volume 9 : 1, 2019 (e-ISSN 2620-8210 | p-ISSN 2088-3226)
} 
mana yang baik dan mana yang buruk dengan memperhatikan amal perbuatan manusia sejauh yang dapat diketahui oleh akal pikiran. $^{3}$

Ada orang berpendapat bahwa etika sama dengan akhlak. Persamaan itu memang ada, karena keduanya membahas masalah baik dan buruknya tingkah laku manusia. Tujuan etika dalam pandangan filsafat ialah mendapat ide yang sama bagi seluruh manusia disetiap waktu dan tempat tentang ukuran tingkah laku dan ukuran yang baik dan yang buruk sejauh yang diketahui akal pikiran manusia. Akan tetapi dalam usaha mencapai tujuan itu, etika mengalami kesulitan, karena pandangan masing-masing golongan di dunia ini tentang baik dan buruk mempunyai ukuran (kriteria) yang berlainan.

Sebagai cabang dari filsafat, maka etika bertitik tolak dari akal pikiran, tidak dari agama. Di sini letak perbedaannya dengan akhlak dalam pandangan Islam. Dalam pandangan Islam, ilmu akhlak ialah suatu ilmu pengetahuan yang mengajarkan mana yang baik dan mana yang buruk berdasarkan ajaran Allah dan RasulNya. Ajaran etika Islam sesuai dengan fitrah dan akal pikiran yang lurus. Demikian juga halnya persamaan etika dan moral. Namun ada pula perbedaannya, yakni etika lebih banyak bersifat teori, sedangkan moral lebih banyak bersifat praktis.

Menurut K. Bertens, moral adalah nilai-nilai dan normanorma yang menjadi pegangan bagi seorang atau kelompok dalam mengatur tingkah lakunya. Makna yang hapir sama untuk kata moral juga ditampilkan oleh Lorens Bagus yang mengungkapkan anttara lain, menyakut kegiatan-kegiatan manusia yang dipandang sebagai baik/buruk, tepat/tidak tepat, atau menyangkut cara seseorang bertingkah laku dalam hubungan dengan orang lain. ${ }^{4}$

Dari pengertian diatas, kata moral itu memuat dua hal yang amat pokok yakni, 1) sebagai cara seseorang atau kelompok

\footnotetext{
${ }^{3}$ Ibid. hlm.13
}

${ }^{4}$ Amril. M, Etika Islam Telaah Pemikiran Filsafat Moral Raghib al-Isfahani (Yogyakarta: Pustaka Pelajar, 2002). 
bertingkah laku dengan orang atau kelompok lain, 2) adanya norma-norma atau nilai-nilai yang menjadi dasar bagi cara bertingkah laku. ${ }^{5}$

Dalam rangka membina dan memperkuat sendi-sendi nilai dan moral masyarakat Islam, Raja Ali Haji telah menyumbangkan ide-ide cemerlang untuk masyarakatnya, terutama dalam keryanya Gurindam Dua Belas yang sarat dengan nilai-nilai moral. Dalam Gurindam Dua Belas Beliau menginginkan suatu kehidupan yang teratur dalam keluarga, masyarakat, bangsa, dan negara, yang terpenting adalah individu itu sendiri.

Gurindam Dua Belas memuat nilai-nilai moralitas manusia terhadap Tuhan dan sesamanya. Bagaimana sebenarnya moral tersebut dalam pandangan Raja Ali Haji dan pendekatan apa yang digunakan dalam penanaman moral tersenut serta bagaimana coraknya, untuk itu diperlukan upaya penelitian ini. Bertitik tolak dari uraian di atas, penulis tertarik untuk mengangkat tema Nilainilai Pendidikan Moral di Lingkungan Masyarakat Sosial dalam Gurindam Dua Belas Karya Raja Ali Haji.

\section{Metode Penelitian}

Metode penelitian yang digunakan dalam artikel ini adalah jenis studi pustaka (library research). Penulis mencermati hasilhasil studi yang diterbitkan baik dalam bentuk buku maupun artikel yang dimuat di jurnal, kemudian merangkumnya menjadi tulisan artikel.

\section{Pembahasan dan Hasil}

Manusia adalah makhluk individu dan makhluk sosial. Manusia sebagai makhluk individu tidak bisa hidup sendirian, tetapi hidup berkelompok. Kelompok manusia yang paling kecil disebut Keluarga dan kelompok besar disebut bangsa. ${ }^{6}$ Dalam

\section{${ }^{5}$ lbid.}

${ }^{6}$ Soewardi MS, Budaya Melayu dalam Perjalanannya Menuju Masa Depan (Pekanbaru: Yayasan Penerbit MSI Riau, 1991).

54 Jurnal Madania: Volume 9 : 1, 2019 (e-ISSN 2620-8210 | p-ISSN 2088-3226) 
hidup berkelompok tersebut tentu harus ada aturan-aturan, norma-norma, dan nilai-nilai moral yang mengaturnya. Raja Ali Haji meletakkan aturan-aturan moral bagi masyarakat melalui hasil karyanya Gurindam Dua Belas.

Raja Ali Haji menyakini bahwa manusia adalah ciptaan Allah dan pada akhirnya kembali kepada-Nya. Namun bukan berarti manusia melupakan kehidupannya sebagai anggota masyarakat. Islam memberikan kepada manusia tolak ukur yang pantas untuk memenuhi kebutuhan psikologisnya, termasuk di dalamnya hidup dengan masyarakat dengan menghargai cinta diri dan bukan egoisme. Cinta diri adalah suatu tanda kebesaran spiritual dan kepribadian yang besar, yang mendorong manusia ke arah sederhana dan pengorbanan. Sebaliknya, egoisme membatasi cakupan pikiran dan menjuruskan watak manusia kedalam kehinaan dan kesusahan. $^{7}$ Egoisme mengorbankan orang lain untuk keingginan dan kesenangan diri sendiri.

Karena itulah Raja Ali Haji sangat menekankan pada pembinaan nilai-nilai moral manusia tehadap manusia lainya, seperti tercermin dalam pasal ke lima berikut ini: ${ }^{8}$

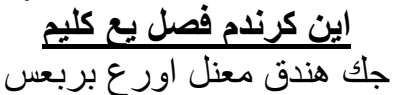

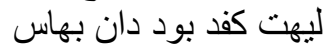

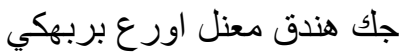

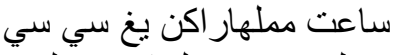

$$
\begin{aligned}
& \text { جك هندق معنل اور عن ملي دئي }
\end{aligned}
$$

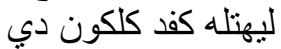

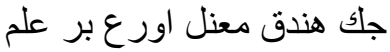

$$
\begin{aligned}
& \text { برتان دان بلاجر تيداله جمو هون }
\end{aligned}
$$

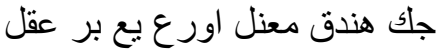

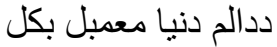

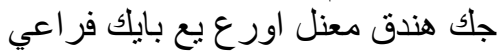

$$
\begin{aligned}
& \text { ليهت فد كتيك برجمفر داعن اورع بع رائ فري }
\end{aligned}
$$

${ }^{7}$ Sayid Mujtaba Musawi Lari, Kata Penghantar dalam Etika dan Pertumbuhan Spiritual (Jakarta: Lentera, 2001).

${ }^{8}$ Raja Ali Haji, Gurindam Dua Belas (Lingga: Pejabat kerjaan Lingga, 1311). 
ليهت كفد بود دان بهاس *جك هندق معنل اورع بربعس. Bait ini mengaskan bahwa orang berbangsa itu adalah orang yang punya martabat, punya jati diri yang terpuji. Hal ini dipantulkan dalam budi dan bahasa. Dengan demikian bangsa dengan masyarakatnya yang baik adalah bangsa yang para anggota masyarakatnya memiliki akhlak yang mulia dan berbudi pekerti yang luhur. ${ }^{9}$

ساعت مملهار اكن يغ سي سي *جك هندق معنل اورع بربهكي. Orang yang berbahagia adalah orang yang memelihara dirinya dari perbuatan yang sia- sia. Dalam Thamaral al muhimmah dijelaskan bahwa perbuatan yang sia-sia itu adalah perbuatan lalai dan lengah, seperti lengah dalam bermain catur, lengah dengan bermain biola, musik dan nyayian sehingga semua waktu terbuang pada hal-hal tersebut yang mengakibatkan lupa waktu dan lupa Shalat. Jadi hendaklah pelihara diri dari melakukan hal-hal yang tidak berguna.

ليهنله كفد كلكون دي *جك هندق معنل اورع ملي. Orang yang mulia adalah orang mempunyai tingkah laku yang baik, berbudi pekerti yang baik dan melaksanakan Amar ma'ruf nahi mungkar. Dengan demikaian orang mulia itu adalah orang yang bertaqwa, lebih tegasnya lagi orang yang bertaqwa itu adalah orang yang berakhlak mulia, karena tujuan akhir dari pelaksanaan ibadah adalah pembinaan dan pembentukan akhlak mulia.

برنان دان بلاجر تيداله جمو *جك هندق معنل اورع بر علم Bait ini mengambarkan bahwa orang yang berilmu itu adalah orang yang mau bertaya dan belajar sungguh-sungguh tanpa jemu. Islam tidak memberikan batas umur dalam menuntut ilmu. IImu yang dipelajari itu tidak terbatas pada ilmu agama saja tapi juga ilmu umum. Dalam hal belajar dan menunutut ilmu, Islam tidak membedaka antara laki-laki dan perempuan. Seperti sabda Nabi:

طلب العلم فريضة علي كل مسلم ومسلمة Artinya : Belajar menuntut ilmu itu adalah kewajiban setiap muslim lelaki dan perempuan. ${ }^{10}$

دالم دنيا معمبل بكل *جك هندق معنل اورع يع بر عقل. Orang yang berakal adalah orang yang dapat membedakan perbuatan baik dan buruk,

\footnotetext{
${ }^{9}$ Harun Nasution, Islam Regional Gagasan dan Pemikiran (Bandung: Mizan, 1994).

${ }^{10}$ Sunan Ibnu Majah Ibnu Majah, Abu Abdullah Muhammad bin Yazid bin Majah ar-Rabi'i al-

Qazwini, Muqaddimah juz I bab IV hadist 233 (Indonesia: Maktabah Dahlan).
}

56 Jurnal Madania: Volume 9 : 1, 2019 (e-ISSN 2620-8210 | p-ISSN 2088-3226) 
suruhan atau larangan. Karena itulah orang berakal akan menggunakan hidupnya di dunia ini untuk mencari bekal di akhirat kelak. Karena ia sadar bahwa dunia ini adalah jembatan untuk sampai ke akhirat. Jadi orang yang berakal tidak akan terpedaya oleh dunia yang fana ini.

$$
\text { ليهت فد كتيك برجمفر داعن اورع رامي *جك هندق معنل اورع يع بايك فر اعي. Pada }
$$

bait ini Raja Ali Haji mengungkapkan jika hendak mengenal orang yang baik perangai maka dapat dilihat pada ketika barkumpul dengan orang ramai. Hal ini menandakan bahwa orang yang mempunyai budi pekerti yang baik dapat dilihat ketika ia bergaul dengan orang ramai. Sikap dan perilakunya akan terwujud dalam pergaulan tersebut. Dengan demikian melalui pergaulan itu akan terlihat siapa yang baik perangainya dan siapa yang tidak baik perangainya.

Dalam hidup bermasyarakat, Raja Ali Haji menanamkan nilainilai pendidikan moral sebagai panduan atau tanda masyarakat yang baik. Hal ini tercantum dalam pasal keenam :11

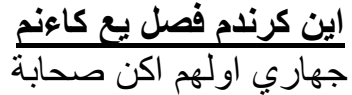

$$
\begin{aligned}
& \text { يع بوله دجديكن اوبت الته } \\
& \text { جهاري اولهم اكن كورو بوري } \\
& \text { يع بوله تهو كن تيف سترو اكن اكورو } \\
& \text { جهاري اولهم اكن استري } \\
& \text { يع بوله دسر هكن ديري } \\
& \text { جهاري اولهم اكن كاون } \\
& \text { فيله سكل اورع يع ستياون أون كان } \\
& \text { جهاري اولهم اكن عبد البد } \\
& \text { يع اد بائيك سديكت بدي }
\end{aligned}
$$

Bait ini memberi pedoman kepada manusia dalam memilih sahabat. Carilah sahabat yang betulbetul baik hati, perangai dan tingkah lakunya, yang dapat dijadikan obat diwaktu susah dan sakit, selalu menghibur kata-kata dan nasehat yang bisa jadi penawar. Sahabat yang baik adalah sahabat yang setia dalam susah maupun duka. Apabila salah mencari sahabat maka akan terjadi penyakit atau racun bagi seseorang.

يع بوله تهو كن تيف سترو *جهاري اولهم اكن كورو Bait ini menjelaskan

${ }^{11}$ Haji, Gurindam Dua Belas.hIm.4 
bahwa apabila mencari guru hendaklah orang yang benar-benar mau mendidik, mengajar dan membimbing dengan sepenuh hati. Sehingga hasil didikan dan bimbingan itu benar-benar dapat membedakan mana yang salah dan mana yang benar, mana yang baik dan mana yang tidak baik.

يع بوله دسر هكن ديري *جهاري اولهم اكن استري Begitu juga dalam mencari istri, Raja Ali Haji melalui bait ini menganjurkan agar berhati-hati dalam memilih wanita yang akan dijadikan istri, Karena istrilah yang bertanggung jawab dalam mengurus rumah tangga, mengasuh dan mendidik anak. Maka pilihlah wanita yang shalehah yang mau menyerahkan diri yaitu apabila melihatnya membuatmu senang, apabila menyuruhnya ia patuh dan taat.

فيله سكل اورع يع ستياون *جهاري اولهم اكن كاون. Begitu juga dalam mencari kawan, harus seleksi dan dipilih. Pilihlah kawan yang mempunyai hati dan sikap yang baik, tidak sombong dan setia baik di kala suka ataupun duka.

Bait ini mengingatkan apabila ingin mencari abdi atau pembatu maka carilah orang yang berbudi pekerti yang baik, supaya dalam bekerja dan bergaul dapat mematuhi adab dan sopan satun.

Selanjutnya pada pasal ketujuh mengadung nilai-nilai yang mengajarkan agar selalu bersikap bijaksana baik dalam perkataan maupun perbuatan. ${ }^{12}$

$$
\begin{aligned}
& \text { اين كرندم فصل بيع كتوجه }
\end{aligned}
$$

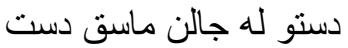

$$
\begin{aligned}
& \text { افبيل بيق برلبه لبهن سوك دك دوك } \\
& \text { اتوله تتد همفر كن دوك لكوك } \\
& \text { افبيل كيت كور ع سياست كن نون } \\
& \text { انوله تند فكرجاءن هندق سست } \\
& \text { افبيل انق تبدق دلاعن تهن } \\
& \text { جلك بسر بفان لته } \\
& \text { افبيل بايق منجلا اورع لئ } \\
& \text { ايتوله تتد درين كورع }
\end{aligned}
$$

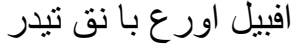

$$
\begin{aligned}
& \text { سي سي سهجا له عمر تبر }
\end{aligned}
$$




$$
\begin{aligned}
& \text { افبيل مندعر اكن حبر } \\
& \text { منريمان ايت هندقله صبر اكن إندر } \\
& \text { افبيل مندعر اكن ادون هندئ }
\end{aligned}
$$

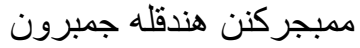

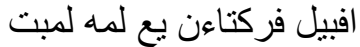

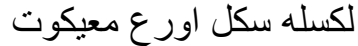

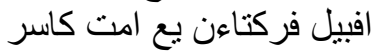

$$
\begin{aligned}
& \text { لكسله اور ع سكلين كوسر فيع امتر }
\end{aligned}
$$

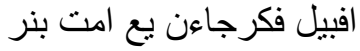

$$
\begin{aligned}
& \text { تيدق بوله اورع بربوت هونر }
\end{aligned}
$$

دسنو له جالن ماست دست *|فييل بيق بركا ت كات. Bait ini mengambarkan tentang bahaya mulut dan lidah bagi manusia. Karena apabila banyak berkata-kata niscaya masuk atau timbul peluang untuk berdusta. Sedangkan dusta itu adalah perbuatan yang tercela yang dilarang oleh agama. Maka apabila berkata-kata hendaklah dipikirkan dahulu apa yang akan diucapkan, sebab jika tidak, perkataan tidak akan terkontrol oleh akal dan akibatnya keluarlah perkataan yang tidak benar.

اتوله تتد همفر كن دوك *|فبيل بيق برلبه لبهن سوك . Melalui bait ini Raja Ali Haji mengingatkan supaya tidak berlebih-lebihan dalam mendapatkan suka, sebab berlebihan suka itu akan mengudang duka. Berlebih-lebihan suka itu seperti tetawa terbahak-bahak yang akhirnya akan mengundang tangis.

اتوله تند فكرجاءن هندق سست . Maksudnya yaitu apabila hendak melakukan suatu pekerjaan hendaklah dipikir secara baik dan matang. Mengkaji kemungkinan sebab dan akibatnya, supaya pekerjaan itu tidak menyalahi aturan dan norma-norma yang berlaku. Sebab apabila dalam melakukan suatu perbuatan tidak dipertimbangkan dengan baik maka alamatlah pekerjaan itu tidak akan sempurna dan sesat.

جك بسر بفان لته *|فبيل انق تيدق دلا ته Bait ini menjelaskan apabila anak tidak dididik dan dibina maka anak itu tidak akan menjadi anak yang shaleh. Dengan demikian jelaslah bahwa bilamana orang tua tidak bisa mengurus dan mendidik anaknya serta anaknya tidak tahu kewajiban yang harus dilaksanakan, maka anak tersebut akan menyusahkan orang tuanya.

ايتوله تند درين كورع *|فييل بايق منجلا اورع Derajat keislaman seorang 
muslim itu berbeda-beda, ada yang tinggi dan ada yang rendah, ada yang sempurna dan ada pula yang kurang sempurna. Perbuatan yang dapat membawa kepada ketinggian atau kesempurnaan keislaman seseorang adalah perbuatan yang tidak menganggu atau menyakiti hati orang muslim lainnya. Mencela adalah salah satu perbuatan yang dapat menyakiti hati orang lain dan menandakan bahwa orang itu rendah atau kurang sempurna keislamannya.

سي سي سهجا له عمر *|فبيل اورع با نق تيدر. Menurut ilmu kesehatan istirahat yang paling baik itu adalah tidur. Tapi tidur juga ada aturannya. Jika malam jangan tidur lebih dari delapan jam, dan jika siang jangan tidur lebih dari satu jam. ${ }^{13}$ Karena banyak tidur itu akan mensia-siakan waktu dan umur serta menghilangkan cahaya muka.

منريمان ايت هندقله صبر *فافيل مندعر اكن حبر. Raja Ali Haji mengingatkan bahwa apabila mendengarkan suatu kabar atau berita, hendaklah menerimanya dengan sabar supaya kabar yang didengar itu jelas adanya. Dan dengan sabar itu tentunya akan menjernihkan akal dikepala, demikian khabar yang diterima itu dapat dipikirkan dan direnungkan kembali benar atau salahnya.

ممبجركن هندقله جمبرون **|فبيل مندعر اكن ادون Melalui bait Ini Raja Ali Haji menjelaskan tentang pengaduan. Apabila datang pengaduan maka hedaklah mendengarkan dengan sabar dan periksa antara kedua dua pihak yang mengadu. Jangan terburu-buru menjawabnya, tanyakan sebabnya dan bermusyawarahlah dahulu sebelum memberi keputusan agar tidak ada pihak yang merasa dirugikan. ${ }^{14}$

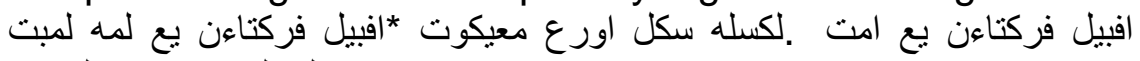
لكسله اورع سكلين كوسر شكاسر. Manusia sebagai makhluk sosial, dalam pergaulan sehari-hari tentu berhubungan dengan manusia lainnya. Maka dalam berkomunikasi hendaklah mengunakan perkataan dan bahasa yang lemah lembut, agar orang yang mendengar merasa senang. Sebaliknya apabila berkata kasar maka orang tentu tidak senang mendengarnya. Hal inni sesuai dengan firman Allah surah Luqman: 19,

$$
\text { و اقصد في مشيك واغضض من صوتك إن أنكر الأصوات لصوت الحمير }
$$

\footnotetext{
${ }^{13}$ Samratu Muhimmah Cut Riowati Aziz, Sutingan Naskah dan Pengkajian Isi (Jakarta: Departemen Pendidikan dan Kebudayaan, Proyek Penerbitan Buku Sastra Indonesia dan Daerah, 1982).
}

${ }^{14}$ Hasan Junus, Muqaddimah fi Intizam.

60 Jurnal Madania: Volume 9 : 1, 2019 (e-ISSN 2620-8210 | p-ISSN 2088-3226) 
Artinya : Dan sederhanalah kamu dalam berjalan dan lunakkanlah suaramu. Sesungguhnya seburuk-buruk suara ialah suara keledai.

$$
\text { . تيدق بوله اورع بربوت هونر|فبيل فكرجاءن يع امت بنر Bait ini }
$$
menerangkan bahwa pekerjaan yang benar itu adalah pekerjaan yang tidak bertentangan dengan ajaran agama. Karena itu pekerjaan yang benar tentu tidak akan membuat onar atau keributan.

Raja Ali Haji juga mengingatkan manusia sebagai makhluk sosial tentunya sangat bergantung pada orang lain. Namun dalam pergaulan sehari-hari tentu ada batas-batas, nilai-nilai dan normanorma yang harus dipatuhi agar tidak terjerumus pada perbuatan yang tidak baik yang merupakan keinginan syaitan. Hal ini diungkapkan dalam pasal kesembilan. ${ }^{15}$

$$
\begin{aligned}
& \text { اين كرندم فصل يع كسمبيلن }
\end{aligned}
$$

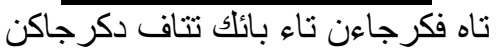

$$
\begin{aligned}
& \text { بوكنن مانسي ياءتو له شيطان تيان } \\
& \text { كجهاتن سؤر ع فرمفون تون الئوان } \\
& \text { ايتو له ابليس فون فغكاو }
\end{aligned}
$$

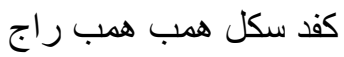

$$
\begin{aligned}
& \text { دسيتو له شبطان تمفتن منج }
\end{aligned}
$$

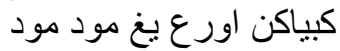

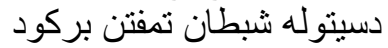

$$
\begin{aligned}
& \text { فر كمفولن لكي لكي دعن فرمفون بن بركن } \\
& \text { دسيتوله شبطان فون جمون دئ دون }
\end{aligned}
$$

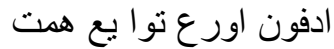

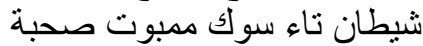

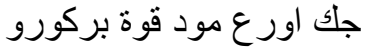

$$
\begin{aligned}
& \text { دعن شيطان جاد برسترو بركورو }
\end{aligned}
$$

بوكن مانسي ياءتو له شبطان *تاه فكرجاءن تاء بائك تتاف دكرجاكن. Melalui bait ini Raja Ali Haji menghimbau supaya meninggalkan perbuatan yang tidak baik, seperti berjudi, mabuk-mabukan, bermusuh-musuhan, dan sebagainya. Perbuatan tersebut adalah perbuatan syaitan. Perbuatan tercela tersebut mendatangkan malapetaka bagi

${ }^{15}$ Haji, Gurindam Dua Belas. 
kehidupan manusia. Orang yang sudah tahu pekerjaan seperti itu tidak baik tapi dikerjakan juga sama halnya dengan syaitan. Sebagaimana firman Allah dalam surat al-Maidah ayat 91, yang artinya "Sesungguhnya syaitan itu bermaksud hendak menimbulkan permusuhan dan kebencian, diantara kamu lantaran (meminum) khamar dan berjudi, dan menghalangi kamu dari mengingat Allah dan sembahyang; maka berhentilah kamu (dari mengerjakan itu).

ايتو له ابليس فون فغكاو *كجهاتن سؤرع فرمفون نوا. Perbuatan jahat perempuan tua adalah akibat dari rayuan kelompok iblis yang menginginkan keburukan bagi manusia tua maupun muda. Karena itulah penuhi diri dengan sifat-sifat yang baik untuk menangkal rayuan iblis tersebut.

$$
\begin{aligned}
& \text { دسيتوله شبطان تمفتن منج *كفد سكل همب همب راج } \\
& \text { دسيتو له شبطان تمفتن بركود * كبياكن اور ع يخ مود مود }
\end{aligned}
$$

Maksud dari bait ini adalah biasanya orang muda-muda itu suka bergaul dan membuat perkumpulan yang tak jarang bermotif hura-hura dan berfoya-foya. Disuasana seperti itulah syaitaan mudah menggoda hamba-hamba Allah. Karena itu dalam bargaul hendaklah berhati-hati agar terhindar dari godaan syaitan.

ديتوله شبطان فون جمون *فر كمفولن لكي لكي دعن فرمفون Bait ini mengingatkan pada manusia baik laki-laki maupun perempuan agar selalu berhati-hati dalam bergaul. Terlebih lagi pada acaraacara tertentu yang menyebabkan terjadinya perkumpulan laki-laki dan perempuan. Seperti acara pesta yang diadakan muda-mudi atau tempat-tempat hiburan (diskotik). Di sanalah kesempatan untuk melakukan pekerjaan yang sifatnya menurut kehendak syaitan mudah terwujud, seperti minum arak, menghisap narkoba, berzina dan lain-lain yang sifatnya negatif dan dilarang dalam Islam.

$$
\text { شيطان تاء سوك ممبوت صحبة *ادفون اورع توا يع همت. Hal ini }
$$
menganjurkan kepada manusia untuk hidup hemat, tidak suka berpoya-poya dan menghamburkan uang yang bersifat mubazir. Sebab orang yang mubazir itu adalah sahabat dan saudara syaitan, sebagaimana firman Allah dalam surat al-Isra' ayat 27 artinya: "Sesungguhnya pemboros-pemboros itu adalah saudara-saudara syaitan dan syaitan itu adalah sangat ingkar pada Tuhannya.

دعن شيطان جاد برسترو *جك اورع مود قوة بركورو. Bait ini menggambarkan bahwa orang mau berguru (menuntut ilmu) akan 
menjadi musuh syaitan. Karena orang yang beilmu dan yang mau mengamalkan ilmu yang diperolehnya tidak akan melakukan perbuatan yang tercela yang diinginkan syaitan.

Dalam pembanggunan kehidupan keluarga, Allah menjelaskan dalam surat al-Tahrim ayat 6 yang artinya: "Hai orangorang yang beriman, peliharalah dirimu dan keluargamu dari api neraka yang bahan bakarnya adalah manusia dan batu; penjaganya malaikat-malaikat yang kasar, yang keras, yang tidak mendurhakai Allah terhadap apa yang telah diperintahkan-Nya kepada mereka dan selalu mengerjakan apa yang diperintahkan.

Ayat di atas menjelaskan bahwa dalam rumah tangga yang bertanggunga jawab untuk menetukan nasib keluarganya adalah orang tua. Orang tua harus apat mengarahkan anaknya kepada kebaikan, sebaliknya anak juga diharapkan memperhatikan nasehat orang tuanya. Dengan demikian akan tercipta keluarga yang baik dan harmonis. Hal ini diungkapkan oleh Raja Ali Haji dalam Gurindam Dua Belas pasal kesepuluh. ${ }^{16}$

$$
\begin{aligned}
& \text { اين كرندم فصل بع كسفوليه } \\
& \text { سفاي الله تيدق مرك درك } \\
& \text { دغن ايب هندقله حرمت درت } \\
& \text { سفاي بدن دافت سلامت دن داثل } \\
& \text { دعن انق جاغنله لالي داني } \\
& \text { سفاي بوله ناءيك كتعه بالي } \\
& \text { دعن استري دان كندق جاعنله الف بن باعن } \\
& \text { سفاي كملون جاعن منرف داعن } \\
& \text { دعن كاون هندقله عادل } \\
& \text { سفابي تاعنن جاد كافل }
\end{aligned}
$$

سفاي بدن *دغن ايب هندقله حرمت .سفاي الله تيدق مرك *دعن باف جاعن درهك . Melalui dua bait diatas, Raja Ali Haji dengan bahasa yang halus berusaha memberikan pedoman dan pelajaran yang baik terutama tentang Perilaku anak terhadap orang tuanya. Anak yang baik adalah anak yang berbakti kepada kedua orang tuanya, tidak durhaka dan selalu menghormatinya. Hal ini sejalan dengan

${ }^{16}$ Haji, Gurindam Dua Belas. 
pandangan Islam seperti yang terdapat dalam surat al-Ahqaaf ayat 15 yang artinya: Kami perintahkan kepada manusia supaya berbuat baik kepada kedua ibu bapaknya, ibunya yang mengadungnya dengan susah payah, dan melahirkan dengan susah payah pula. Mengandungnya sampai menyapihnya selama tiga puluh bulan.

Allah menyuruh manusia untuk selalu berbuat baik kepada orang tua, agar hidupnya selamat baik di dunia maupun di akhirat. Dalam menyapaikan nilai-nilai moral seperti ini Raja Ali Haji mempergunakan caranya melalui syair, sehingga memudahkan masyarakat untuk memahami apa yang disampaikan tersebut. Tapi memang pada masa itu masyarakat sangat menggemar syair-syair yang bersifat puitis.

سفاب بوله ناءيك كتعه بالي *دعن انق جاغنله لالي Anak bagi orang tua adalah amanah Allah yang harus dirawat dan diasuh dengan penuh tanggung jawab. Merawat dan mengasuh anak berarti membesarkannya menjadi anak yang sehat baik fisik maupun mentalnya, serta mendidiknya sehingga kelak menjadi anak yang berguna bangi masyarakat dan bangsanya. Jika orang tua dapat melaksanakan hal tersebut dengan baik tentu ia akan merasa kenahagiaan atas hasil didikannya tersebut. Akan tetapi bilamana sebaliknya orang tua lalai atau tidak bisa mengurus dan mendidik anaknya maka anak tersebut akan menyusahkan orang tua.

سفاي كملون جاعن منرف *دعن استري دان كندق جاعنله الف. Bait ini mengingatkan kepada manusia khususnya para raja supaya jangan lupa dan alpa pada istri dan gundiknya. Istrilah yang harus dipergauli dengan baik. Sebab jika tidak, tentu perbuatannya terutama anggota tenggah dari tubuhnya yang akan menerpa wanita lain.

سفاي تاعنن جاد كافل *دعن كاون هندقله عادل. Bait ini menegaskan kepada manusia untuk selalu berlaku adil dalam segala situasi, baik terhadap musuh maupun terhadap kawan. Rasa keadilan harus dapat mengatasi hawa nafsu, kepentingan pribadi dan rasa kasih sayang maupun rasa benci. Dengan berlaku adil pada kawan, diharapkan tangannya terbiasa melakukan perbuatan adil. Allah menegaskan perlunya bersikap adil karena keadilan merupakan jalan terdekat kepada taqwa. Tanpa keadilan akan timbul maksiat dan kerusakan yang akan menghancurkan sendi-sendi kehidupan sosial. 
Raja Ali Haji juga mengingatkan manusia terutama para pemimpin supaya dapat menjadi panutan bagi masyarakat. Untuk itu mereka harus memperhatikan panduan nilai-nilai moral dalam bergaul dengan masayarakat. Hal ini diungkapkan dalam pasal kesebelas. ${ }^{17}$

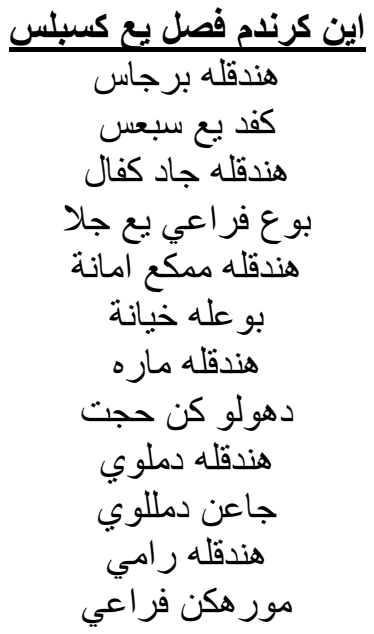

كait ini menganjurkan kepada manusia bahwa dalam pergaulan bermasyarakat terutama dalam berbangsa hendaklah berjasa. Berjasa disini maksudnya perbuatan yang baik dan berguna. Karena itu sebagai masayarakat dan warga negara yang baik hendaklah melakukan perbuatan yang baik dan berguna bagi bangsanya.

بوع فراعي يع جلا *هندقله جاد كفال. Pada bait ini Raja Ali Haji mengingatkan manusia yang ingin menjadi kapala atau pemimpin supaya membuang perangai yang tidak baik dan tercela seperti yang terdapat dalam pasal ke sebelas diatas. Karena seorang pemimpin itu akan menjadi contoh teladan bagi masyarakat.

بو عله خيانة *هندقله ممكع امانة. Pada bait ini Raja Ali Haji berpesan supaya memegang amanah yang dipercayakan kepadanya, baik masalah keluarga maupun bangsa. Amanah merupakan salah satu dari sifat terpuji yang harus terus dibina dan dipelihara. Lawanya adalah khianat. Khianat berarti tidak memegang amanah yang diberi kepadanya, dan ini merupakan perbuatan yang sangat tercela dan

17 Ibid. 
termasuk kedalam ciri-ciri manusia munafik.

. دهولو كن حجت * هندقله ماره Persoalan marah sebenarnya juga telah dibahas pada pasal keempat bait keempat. Pada bait ini diterangkan bahwa apabila hendak marah maka hendak dahulukan hujjah yaitu dalil, keterangan atau penjelasan. Jadi apabila mau marah pada seseorang karena perbuatannya, maka tanyakan dulu apa sebabnya ia melakukan perbuatan tersebut. Dengarkan dulu penjelasan dan keterangannya, dan jangan asal marah yang mengikuti hawa nafsu.

جاعن دمللوي *هندقله دملوي. Bait ini memberi panduan dalam pergaulan dengan masyarakat, yaitu apabila tidak mau dimalui maka jangan memalui, yaitu jangan memalukan orang kalau tidak mau diberi malu oleh orang lain. Dalam Islam sangat dianjurkan untuk memelihara rasa malu, karena malu itu merupakan bagian dari iman.

مورهكن فراعي *هندقله رامي. Raja Ali Haji melalui bait ini menjelaskan bahwa apabila ingin ramai dalam arti mempunyai teman yang banyak, maka dalam pergaulan sehari-hari hendaklah murahkan perangai dalam arti tidak sombong, ramah tamah, sopan santun. Dengan demikian tentu banyak orang yang senang bergaul dan akhirnya mempunyai teman yang banyak.

Orang Melayu, khususnya orang Melayu Riau, seperti terhadap dalam ungkapan-ungkapan bermakna yang menunjukkan sikap hidup kemanusiaan, persatuan, musyawarah, dan keadialan sosial. Ungkapan tersebut seperti dimuat dalam Gurindam Dua Belas pasal keduabelas. ${ }^{18}$

$$
\begin{aligned}
& \text { اين كرندم فصل بع كدوبلس دعن منتري } \\
& \text { سفرتي كبن برفاكركن دوري } \\
& \text { بتل هات كفد راج } \\
& \text { تند جاد سبار ع كرج } \\
& \text { حكم عادل اتس رعيت } \\
& \text { تند راج بر او لله عنا ية } \\
& \text { كاسهكن اور ع يع بر علمو له } \\
& \text { تند رحمة اتس دريم } \\
& \text { حرمة اكن اورع يع فندي }
\end{aligned}
$$

18 Ibid. 


$$
\begin{aligned}
& \text { تتد معنل كاس دان جندي } \\
& \text { ايعتكن ديرن مات دات } \\
& \text { اتوله اصل بربوت بقدني } \\
& \text { اخرة ايت تر لال بات برت } \\
& \text { كفد هاتي يع تيدق بوت }
\end{aligned}
$$

سفرتي كبن برفاكركن دوري *راج موفقت دعن منتري Bait ini memberi pedoman kepada penguasa (raja) sebagai pengawal kehidupan pemerintahan dan masyarakat. Raja harus mufakat dengan menterinya, sehingga segala tindakan dan keputusan dapat memberikan kemaslahatan bagi warga masyarakat. Menteri dimaksudkan membantu penguasa mengatur pemerintahan. Dengan adanya menteri, maka pekerjaan berat yang dipikul penguasa akan menjadi ringan berkat bantuan menterinya. ${ }^{19}$

تند راج براو له عنا ية *حكم عادل اتس رعيث. Memberi hukuman kepada rakyat haruslah adil, sehingga tidak ada yang tertindas. Katakan yang benar itu benar, yang salah itu salah. Dalam Muqaddimah fi Intizam dinyatakan bahwa seyogianya para raja atau penguasa memiliki hati rakyatnya. Dan seorang raja harus menjadi perantara atau penegak dalam setiap perselisihan yang terjadi diantara rakyatnya. Seseorang raja tidak akan memerintah dengan sempurna apabila dikalangan rakyatnya penuh dengan orangorang yang saling bermusuhan. Untuk itu diperlukan tindakan bijaksana yang sesuai dengan ajaran agama Islam. ${ }^{20}$

$$
\text { تند معنل *حرمة اكن اورع يع فندي .تند رحمة اتس دريم *كاسهكن اورع يع بر علمو }
$$
. Manusia diberi kelebihan oleh Allah dari makhluk lainya yaitu akal. Akal gunanya untuk berfikir dan mencari ilmu. Itulah rahmat Allah yang paling besar kepada hamba-Nya manusia. Dalam al-Qur'an surat al-Mujadalah ayat 11 yang artinya: Allah swt akan meninggikan orang-orang yang berilmu diantaramu dan orang-orang yang diberi ilmu pengetahuan beberapa derajat.

Kedua bait di atas menggambarkan bahwa akal merupakan suatu keutamaan dalam mencapai kebahagiaan di dunia dan akhirat. Maksudnya kehidupan dunia dimanfaatkan sebagai jalan

${ }^{19}$ Cut Riowati Aziz, Sutingan Naskah dan Pengkajian Isi.

${ }^{20}$ Hasan Junus, Raja Ali Haji dan Karya-Karyanya (Badan Perencanaan Pembangunan Daerah Propinsi Daerah Tingkat I Riau Proyek Pelestarian Seni Budaya Riau). 
untuk mencapai kehidupan yang hakiki di akhirat kelak. Raja Ali Haji memperinggatkan bahwa kehidupan manusia didunia ini akan berakhir dengan suatu kematian, kematian jasmani yang akan memisahkan manusia dari kehidupan duniawi ke kehidupan ukhrawi.

$$
\text { كفد هاتي يع تيدق *اخرة ايت ترلال بات .اتوله اصل بربوت بقتي *ايعتكن ديرن مات }
$$

بوت Raja Ali Haji menghendaki suatu pemahaman bahwa hidup didunia ini singkat dan tentu, sehingga carilah suatu kesempatan untuk berusaha dalam berbuat amal kebajikan. Manusia yang utama adalah manusia yang bisa memadukan fungsi hati dan akal secara baik dan untuk hal-hal yang baik pula. Begitu pula selaku pemimpin atau raja hendaklah sederhana tetapi berbudi mulia, karena ia ingat akan mati seperti manusia lainya. Kesadaran itulah yang mendorong seseorang berbuat kebaikan, sehinga ia punya bekal yang memadai menuju akhirat yang tidak diragukan lagi.

\section{Kesimpulan}

Moralitas manusia sebagai pribadi dan anggota masyarakat, yang diungkapkan Raja Ali Haji melalui pemeliharaan anggota tubuh dari hal-hal yang tidak baik, dan membiasakan diri melakukan perbuatan terpuji dan meninggalkan perbuatan tercela yang tercermin dalam sikap dan tingkah laku sehari-hari akan dapat menghindari kerusakan moral akibat pergaulan yang tidak baik. Jika hal tersebut tetap dibina dan diamalkan oleh setiap manusia maka tentu dekadensi moral yang terjadi saat ini akan dapat diatasi.

Untuk itulah Gurindam Dua Belas yang dikarang oleh Raja Ali Haji ini bukanlah sekedar hasil dari suatu karya sastra belaka, namun ia sarat dengan nilai-nilai moral yang dapat dipedomani oleh segenap lapisan masyarakat baik pada zamannya maupun pada zaman sekarang ini dan bahkan untuk zaman yang akan dating. Hal ini disebabkan karena nilai-nilai moral yang terdapat dalam Gurindam Dua Belas itu tidak hanya bersifat horizontal tapi juga bersifat vertical, dalam arti tidak hanya mengandung nilai-nilai moral manusia dengan sesamanya tapi lebih dari itu mengandung nilai-nilai moral manusia dengan Tuhan. 
Dekadensi moral yang terjadi saat ini akibat perubahan dan kemajuan tekhnologi, disebabkan oleh manusia yang hanya memperhatikan nilai-nilai secara horizontal saja, dalam arti hanya memperhatikan nilai-nilai yang berhubungan dengan sesamanya dan bersifat rasional. Sedangkan nilai-nilai secara vertikal yang berhubungan dengan Tuhan terlupakan. Akibatnya manusia menjadi monoton dan bosan, yang pada akhirnya manusia kembali mencari sesuatu yang terlupakan itu, yakni keyakinan akan adanya suatu kekuatan di atas kekuatan manusia (Tuhan). Salah satu caranya adalah dengan kembali pada karya-karya klasik yang sarat dengan nilai-nilai baik vertikal maupun horizontal seperti halnya Gurindam Dua Belas ini.

\section{Daftar Pustaka}

Cut Riowati Aziz, Samratu Muhimmah, Sutingan Naskah dan

Pengkajian Isi, Jakarta: Departemen Pendidikan dan Kebudayaan,

Proyek Penerbitan Buku Sastra Indonesia dan Daerah, 1982.

Haji, Raja Ali, Gurindam Dua Belas, Lingga: Pejabat kerjaan Lingga, 1311.

Ibnu Majah, Abu Abdullah Muhammad bin Yazid bin Majah ar-Rabi'i alQazwini, Sunan Ibnu Majah, Muqaddimah juz I bab IV hadist 233, Indonesia: Maktabah Dahlan.

Junus, Hasan, Muqaddimah fi Intizam.

----, Raja Ali Haji dan Karya-Karyanya, Badan Perencanaan

Pembangunan Daerah Propinsi Daerah Tingkat I Riau Proyek

Pelestarian Seni Budaya Riau.

Lari, Sayid Mujtaba Musawi, Kata Penghantar dalam Etika dan

Pertumbuhan Spiritual, Jakarta: Lentera, 2001.

M, Amril., Etika Islam Telaah Pemikiran Filsafat Moral Raghib al-

Isfahani, Yogyakarta: Pustaka Pelajar, 2002.

MS, Soewardi, Budaya Melayu dalam Perjalanannya Menuju Masa

Depan, Pekanbaru: Yayasan Penerbit MSI Riau, 1991.

Nasution, Harun, Islam Regional Gagasan dan Pemikiran, Bandung:

Mizan, 1994.

Ya'qub, Hamzah, Etika Islam pembinaan Akhlakul Qarimah (suatu penghantar), Bandung: Diponegoro, 1983. 